\title{
RESEARCH
}

\section{Refined Localization of the Cerebral Cavernous Malformation Gene (CCMI) to a 4-cM Interval of Chromosome 7q Contained in a Well-defined YAC Contig}

\author{
Eric W. Johnson, ${ }^{1,17}$.Leslie M. lyer, ${ }^{2}$ Stephen S. Rich, ${ }^{3}$ Harry T. Orr, ${ }^{4-6}$ \\ Antonio Gil-Nagel, ${ }^{4,7}$ Janice H. Kurth, ${ }^{8}$ Joseph M. Zabramski, ${ }^{8}$ \\ Douglas A. Marchuk, ${ }^{9}$ Jean Weissenbach, ${ }^{10}$ Carol L. Clericuzio, ${ }^{11}$ \\ Larry E. Davis, ${ }^{12}$ Blaine L. Hart, ${ }^{13}$ James F. Gusella, ${ }^{14}$ \\ Barry E. Kosofsky, ${ }^{15}$ David N. Louis, ${ }^{16}$ Leslie A. Morrison, ${ }^{11}$ \\ Eric D. Green, ${ }^{2}$ and James L. Weber ${ }^{1}$
}

\begin{abstract}
${ }^{1}$ Center for Medical Genetics, Marshfield Medical Research Foundation, Marshfield, Wisconsin 54449; ${ }^{2}$ National Center for Human Genome Research, National Institutes of Health, Bethesda, Maryland 20892; ${ }^{3}$ Department of Public Health Sciences and Neurology, Bowman Gray School of Medicine, Wake Forest University, Winston-Salem, North Carolina 27157; ${ }^{4}$ Minnesota Comprehensive Epilepsy Program (MINCEP), ${ }^{5}$ Institute of Human Genetics, ${ }^{6}$ Department of Laboratory Medicine and Pathology, ${ }^{7}$ Department of Neurology, University of Minnesota, Minneapolis, Minnesota 55455; ${ }^{8}$ Barrow Neurological Institute, Phoenix, Arizona 85026, ${ }^{9}$ Department of Genetics, Duke University Medical Center, Durham, North Carolina 27710; ${ }^{10}$ Genethon, 91000 Evry, France; Department of ${ }^{11}$ Pediatrics, ${ }^{12}$ Neurology, and ${ }^{13}$ Radiology, New Mexico School of Medicine, Albuquerque, New Mexico 87131; the ${ }^{14}$ Molecular Neurogenetics Unit, ${ }^{15}$ Neurology Service, and ${ }^{16}$ Department of Pathology, Massachusetts General Hospital and Harvard Medical School, Boston, Massachusetts 02114
\end{abstract}

Cerebral cavernous malformations (CCM) are vascular lesions present in some 20 million people worldwide that are responsible for seizures, migraine, hemorrhage, and other neurologic problems. Familial cases of CCM can be inherited as an autosomal dominant disorder with variable expression. A gene for CCM (CCMI) was recently mapped to a 33-cM segment of chromosome $7 \mathrm{q}$ in a large Hispanic family (Dubovsky et al. 1995). Here, the collection of several new short tandem repeat polymorphisms (STRPs) within the region of interest on $7 \mathrm{q}$ and the refinement of the marker order in this region using both linkage analysis in CEPH families and especially YAC-based STS content mapping are described. Affected members of three Hispanic families share allele haplotypes indicating a common ancestral mutation within these families. Using the shared haplotype information along with analysis of crossovers in affected individuals from both the Hispanic and Caucasian families, the region likely to contain the CCMl gene has been reduced to a 4-cM segment of $7 q$ between D7S2410 and D7S689. All markers within the refined chromosomal segment were located on a single YAC contig estimated to be $\sim 2 \mathrm{Mb}$ in size. Four potential candidate genes have been mapped to this region.

Cerebral cavernous malformations (CCM) (also called cerebral cavernous angiomas or cavernous hemangiomas) are vascular malformations consisting of large, closely clustered enlarged capillary channels (caverns) with a single layer of en-

17 Corresponding author.

E-MAIL johnsone@mfldclin.edu; FAX (715) 389-3808. dothelium and without the normal intervening neural tissue or brain parenchyma. The walls of CCM are devoid of any smooth muscle and elastic tissue. Microscopic hemorrhage, gliosis, and calcification are common (Voight and Yasargil 1976; Simard et al. 1986; Villani et al. 1989). $\mathrm{CCM}$ can range in size from a few millimeters to several centimeters in diameter. 
CCM represent $5 \%-15 \%$ of all cerebral vascular malformations. Affected individuals may have single or multiple lesions, usually in the cerebral hemispheres. Magnetic resonance (MR) imaging is exquisitely sensitive to the presence of hemosiderin and the other breakdown products of blood that characterize these lesions, leading to a highly distinctive appearance that is diagnostic for CCM in the majority of cases (Rigamonti et al. 1987; Zabramski et al. 1994). Two large retrospective reviews of $>22,000$ MR studies have yielded an incidence rate for cavernous malformations of between $0.39 \%$ and $0.47 \%$ in the general population (Curling, 1991; Robinson 1991). This rate is nearly identical to that reported in several autopsy series that included neuropathologic expaminations (McCormick 1984; Otten et al. 1989; Curling et al. 1991; Robinson et al. 1991; Zabramski et al. 1994), and represents between 18 and 22 million people affected worldwide.

CCM have been reported in infants and children, but the majority of patients present with symptoms between the second and fifth decades (Curling et al. 1991; Robinson et al. 1991; Zabramski et al. 1994). Of patients who are MR imaging positive, $15 \%-20 \%$ can remain asymptomatic throughout their lives (Curling et al. 1991; Robinson et al. 1991). Others experience a number of serious neurological problems resulting from intracranial hemorrhage and mass effects, with focal and generalized epileptic seizures being the most common presenting symptom (40\%-70\%), followed by focal neurological deficits $(35 \%-50 \%)$ and nonspecific headache pain (10\%-30\%) (Voight and Yasargil 1976; Simard et al. 1986; Rigamonti et al. 1988; Villani et al. 1989; Curling et al. 1991; Robinson et al. 1991; Zabramski et al. 1994). CCM can also lead to death as a result of cerebrovascular accident (Hayman et al. 1982; Gil-Nagel et al. 1995).

CCM occur in two forms: (1) a spontaneous form in which patients usually present with a single lesion and no family history of neurological disease; and (2) a familial form characterized by multiple lesions and a strong family history of seizures. The familial form of cavernous malformations (FCCM) is inherited as an autosomal dominant disorder with variable expression (Hayman et al. 1982; Dobyns et al. 1987; Rigamonti et al. 1988; Allard et al. 1989; Malik et al. 1992; Zabramski et al. 1994).

A gene for CCM (CCM1) was mapped by our group to a 33-centimorgan (cM) segment of chro- mosome $7 \mathrm{q}$ in a large Hispanic family (Dubovsky et al. 1995). Marchuk and co-workers (1995) demonstrated linkage for CCM to a slightly broader, overlapping 41-cM segment of 7q in two additional families, one Hispanic and one Caucasian. Linkage to this same region of $7 \mathrm{q}$ has also been confirmed in another large Caucasian kindred (Gil-Nagel et al. 1995b). In this family, the gene could be localized to the 15-cM segment of $7 q$ bounded by D7S660 and D7S558. Finally, Günel and colleagues (1995) recently reported linkage to a broad region of $7 \mathrm{q}$ in two additional families, one Hispanic and the other Caucasian of European decent.

Using analysis of crossovers in both affected and unaffected individuals along with common haplotype analysis of affected members from three Hispanic families, we have been able to refine the region likely to contain the CCM1 gene to a 2 -megabase pair $(\mathrm{Mb})$ segment of $7 \mathrm{q}$ between D7S2410 and D7S689.

\section{RESULTS}

\section{Linkage Mapping of $7 \mathrm{q}$ Polymorphic Markers}

A sex-equal linkage map for the region of interest

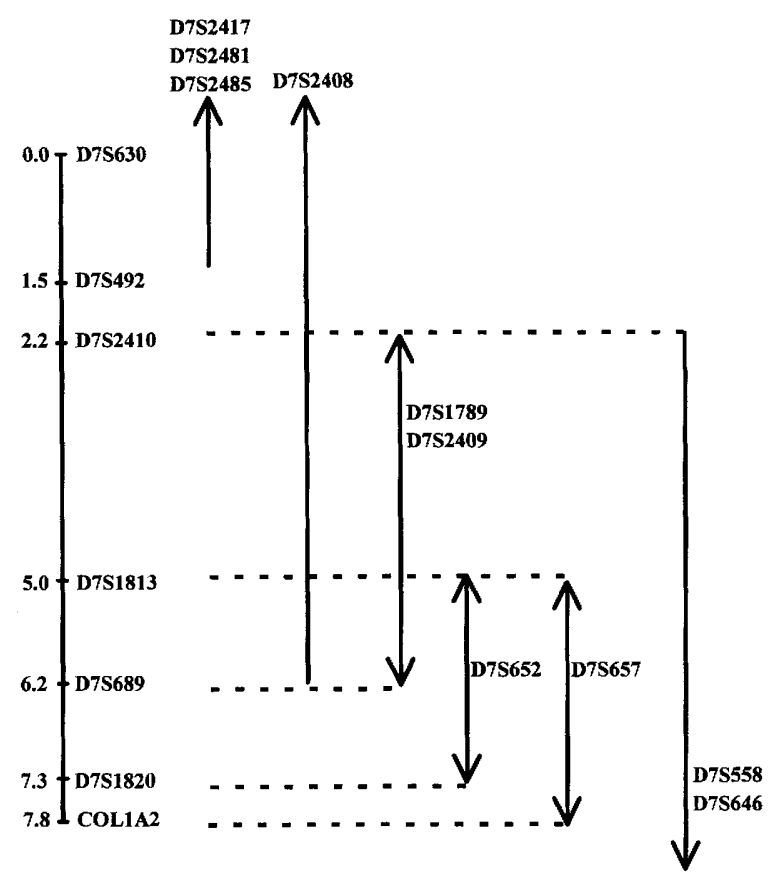

Figure 1 Sex equal linkage map for the region of interest on chromosome $7 \mathrm{q}$. Map distances are listed in cM. Several of the markers could not be completely ordered relative to the others. They are shown at right with the best single-crossover positions indicated. 
JOHNSON ET AL.

\begin{tabular}{|c|c|c|c|c|c|c|}
\hline STS Name & Alias & $\underline{\text { Locus }}$ & Source & $\underline{\text { PCR Primers }}$ & Size (bp) & $\underline{\text { GDB ID }}$ \\
\hline sWSS2102 & & D7S2651 & YAC End & $\begin{array}{l}\text { CATTTCCTAAAAGCGTTTC } \\
\text { TAAGTAATCACCAAGACC }\end{array}$ & 201 & G00-626-855 \\
\hline sWSS1326 & & $\mathrm{D} 7 \mathrm{~S} 2658$ & YAC End & $\begin{array}{l}\text { CAATAACTCTTGGATTGG } \\
\text { GAATTAGTGAACTTGAAGG }\end{array}$ & 135 & G00-626-840 \\
\hline sWSS2637 & & Diš2659 & YAC Insert & $\begin{array}{l}\text { CACATAAGATGCTTCACC } \\
\text { GAGAATACAGTGTTATTTCC }\end{array}$ & 126 & G00-626-864 \\
\hline sWSS2967 & & D7S2660 & YAC End & $\begin{array}{l}\text { TATTGGGAACACAGAGAG } \\
\text { ATAGCACTGTTTACCACATC }\end{array}$ & 103 & G00-626-876 \\
\hline sWSS1228 & AFM158xa1 & D7S492 & Genetic Marker & $\begin{array}{l}\text { GTGTATCCAGAATCTCAG } \\
\text { GGCTCTGCTCCATCTTCATA }\end{array}$ & 231 & G00-307-750 \\
\hline sWSS2073 & & $\mathrm{D} 7 \mathrm{~S} 2661$ & YAC End & $\begin{array}{l}\text { AGGTTGTATGTCTCTATG } \\
\text { AATAAAGAGAGAAGACGG }\end{array}$ & 134 & G00-626-852 \\
\hline sWSS893 & & D7S2662 & Lambda Clone & $\begin{array}{l}\text { AGTAATCCTTGGAGCTTG } \\
\text { GCTATGAAGGCTTTTTAAAC }\end{array}$ & 125 & G00-626-897 \\
\hline sWSS3044 & AFMa218ze5 & D7S2410 & Genetic Marker & $\begin{array}{l}\text { TATAGTGCCAACATCTCC } \\
\text { CCAAGACATTCAGATTTTC }\end{array}$ & 75 & G00-626-882 \\
\hline sWSS1818 & & $\mathrm{D} 7 \mathrm{~S} 2663$ & YAC End & $\begin{array}{l}\text { AATCCTAAGTGTCTAGTG } \\
\text { TTTTCTGGCATAGTGTTG }\end{array}$ & 228 & G00-626-846 \\
\hline sWSS370 & & D7S1426 & M13 Clone & $\begin{array}{l}\text { ATGAGGGTTAGGTTCTTG } \\
\text { ATGGAGAGGTTGAAGTTG }\end{array}$ & 131 & G00-269-209 \\
\hline sWSS1813 & & $\mathrm{D} 7 \mathrm{~S} 2664$ & YAC End & $\begin{array}{l}\text { TGACTTTGTAGTGTAGCC } \\
\text { GTATTGACCTTCACCTTG }\end{array}$ & 109 & G00-626-843 \\
\hline sWSS1968 & & D7S2665 & YAC End & $\begin{array}{l}\text { TTTCAGTGTGTTACAAGG } \\
\text { TGAGTTCTGGAATATAGG }\end{array}$ & 96 & G00-626-849 \\
\hline sWSS409 & & D7S1431 & Lambda Clone & $\begin{array}{l}\text { AATCAGCATTTCCAGGTC } \\
\text { GGCTAAATAGTCCCTAAG }\end{array}$ & 113 & G00-269-224 \\
\hline sWSS2703 & & $\mathrm{D} 7 \mathrm{~S} 2652$ & YAC End & $\begin{array}{l}\text { CATTAAAGTAACTGGAATGG } \\
\text { ACTTCAGGAAAATCTCTATTGG }\end{array}$ & 148 & G00-626-870 \\
\hline sWSS532 & & D7S1539 & Lambda Clone & $\begin{array}{l}\text { CATAGCCAGGATATAAAC } \\
\text { TTGAGCATCTCTAGGAAC }\end{array}$ & 104 & G00-626-894 \\
\hline sWSS3041 & AFM359tf1 & $\mathrm{D} 7 \mathrm{~S} 2408$ & Genetic Marker & $\begin{array}{l}\text { ACGGTTTACTCATTCTGG } \\
\text { GAACATTTCTCTTGCTGG }\end{array}$ & 162 & G00-626-879 \\
\hline sWSS2344 & AFMa202xa5 & D7S2409 & Genetic Marker & $\begin{array}{l}\text { CACAATGTAAGGTGATAG } \\
\text { TTTTTTCCCTCATGCTTC }\end{array}$ & 141 & G00-626-858 \\
\hline sWSS3004 & ATA24A12 & $\mathrm{D} 7 \mathrm{~S} 1813$ & Genetic Marker & $\begin{array}{l}\text { AAGTGCACCCAGCTCCAG } \\
\text { CCTTCTCAGGCTATATTTAGTTAGC }\end{array}$ & 143 & G00-364-997 \\
\hline sWSS3071 & & $\mathrm{D} 7 \mathrm{~S} 2653$ & YAC End & $\begin{array}{l}\text { GTCTCATTTGTTCACTGG } \\
\text { TAAGGTTTAGATACAGAAAGGG }\end{array}$ & 135 & G00-626-885 \\
\hline sWSS2694 & & $\mathrm{D} 7 \mathrm{~S} 2654$ & YAC End & $\begin{array}{l}\text { ACTTTTAACCTGGATCTC } \\
\text { TTTCTCTCTAGTAGCCTG }\end{array}$ & 190 & G00-626-867 \\
\hline sWSS2683 & АСТЗЕ08 & D7S1789 & Genetic Marker & $\begin{array}{l}\text { GAAAACAGTGATAGGAACCTGC } \\
\text { ATTCACCCTGCTCTCTAGGG }\end{array}$ & 131 & G00-364-138 \\
\hline sWSS1708 & EST00272 & D7S535E & EST & $\begin{array}{l}\text { AGTGGTCACTATCTAACTGG } \\
\text { GATTCAGAATTACTAAGCCG }\end{array}$ & 67 & G00-189-116 \\
\hline sWSS1727 & EST00631 & D7S548E & EST & $\begin{array}{l}\text { CATGTATACTGGGGAGTATG } \\
\text { TCAAAGTAGACTTACATCAG }\end{array}$ & 68 & G00-190-983 \\
\hline
\end{tabular}




\begin{tabular}{|c|c|c|c|c|c|c|}
\hline STS Name & $\underline{\text { Alias }}$ & $\underline{\text { Locus }}$ & Source & PCR Primers & Size (bp) & GDB ID \\
\hline sWSS1725 & EST00979 & D7S539E & EST & $\begin{array}{l}\text { GGTTTGGGATAATTTCCTTC } \\
\text { GTTACATTCTGGGTTAGTAT }\end{array}$ & 132 & G00-188-919 \\
\hline sWSS3105 & CDK6 & CDK6 & Gene & $\begin{array}{l}\text { CGGAGAACACCCTTGGTG } \\
\text { GAGCCTGTCCAGAAGACAGC }\end{array}$ & 105 & G00-626-888 \\
\hline sWSS1376 & AFM240ve3 & D7S646 & Genetic Marker & $\begin{array}{l}\text { CTATTTCTTTTCTTGACTGG } \\
\text { CATTTTAACTGCTCAGAC }\end{array}$ & 97 & G00-307-806 \\
\hline sWSS2533 & & $\mathrm{D} 7 \mathrm{~S} 2655$ & YAC End & $\begin{array}{l}\text { GGATTTTACGTGGAATGG } \\
\text { GTGGAGCAATAAAGGTAAG }\end{array}$ & 145 & G00-626-861 \\
\hline sWSS462 & & $\mathrm{D} 7 \mathrm{~S} 2656$ & Lambda Clone & $\begin{array}{l}\text { GATGGTTGTAGATGTGTAG } \\
\text { TGTTTTAAAGCACAACAGCC }\end{array}$ & 72 & G00-626-891 \\
\hline sWSS2689 & MFD267 & D7S558 & Genetic Marker & $\begin{array}{l}\text { CCCTGCCTCTAAAATTATAC } \\
\text { GGAATCTGGTAGACTGGTTT }\end{array}$ & 95 & G00-195-021 \\
\hline sWSS1132 & AFM333wf5 & D7S689 & Genetic Marker & $\begin{array}{l}\text { CCTCAACCTGAATCTCACATC } \\
\text { CAATGGAGCCAGACTCTGT }\end{array}$ & 131 & G00-626-837 \\
\hline sWSS2717 & & D7S2657 & YAC End & $\begin{array}{l}\text { GCAACTTTGTATAATCCC } \\
\text { AGAAAACTCAGACCTCAG }\end{array}$ & 111 & G00-626-873 \\
\hline sWSS1096 & AFM263yd9 & D7S657 & Genetic Marker & $\begin{array}{l}\text { GTCACAGCACAGTTTTTGG } \\
\text { GTCAAGTAGAGATTGAGATTCC }\end{array}$ & 246 & G00-626-834 \\
\hline sWSS2011 & WI- 1840 & D7S1762 & Random Clone & $\begin{array}{l}\text { TCACCTAGGGAGGTCGCTAA } \\
\text { TGCGATAGTCTTATAATTCTTCATGG }\end{array}$ & 204 & G00-354-938 \\
\hline sWSS1091 & AFM254xd5 & D7S652 & Genetic Marker & $\begin{array}{l}\text { GGGCTTGTTTCATTACACGTTG } \\
\text { CATGATTTTTGGCACAGAATGTTAG }\end{array}$ & 275 & G00-626-831 \\
\hline \multicolumn{7}{|c|}{$\begin{array}{l}\text { The } 34 \text { chromosome 7-specific STSs mapped to the YAC contig shown in Fig. } 2 \text { are listed. In each case, the designated sWSS name, } \\
\text { relevant alias, GDB-assigned locus name, STS source, PCR primer sequences, STS size, and GDB identification (ID) number are } \\
\text { provided. The sources of STSs are as follows: YAC End [isolated insert end of a YAC (Green 1993)], YAC Insert (random segment } \\
\text { from a YAC insert), Genetic Marker (STRP), } \lambda \text { Clone [random chromosome 7-specific } \lambda \text { Clone (Green et al. 1991; Green 1993)], } \\
\text { M13 Clone [random M13 clone derived from a flow-sorted chromosome } 7 \text { library (Green et al. 1991; Green 1993)], EST (expressed } \\
\text { sequence tag-specific STS), Gene (gene-specific STS), and Random Clone (random human genomic STS mapped to chromosome } \\
\text { 7). Note that for some genetic marker-specific STSs, the PCR primers used for identifying YACs (listed here) are different from those } \\
\text { used for performing genotype analysis, because the detection of YACs containing a genetic marker does not require amplification } \\
\text { of the polymorphic tract itself. }\end{array}$} \\
\hline
\end{tabular}

is shown in Figure 1. The map was based on typing of the short tandem repeat polymorphic markers through eight large CEPH families. In each case, pairwise marker order was established on the basis of at least one clear recombination event. Because of the limited number of recombination events in the eight families, several of the markers could not be completely ordered relative to the others. These markers are shown on the right with the best single-crossover positions indicated. The dinucleotide short tandem repeat polymorphism (STRP) at locus D7S652, for example, was placed on the map distal to D7S1813 but proximal to D7S1820.

\section{Physical Mapping of the CCMI Critical Region}

As part of a global effort to construct a physical map of human chromosome 7 (Green et al. 1991, 1994,1995 ), a yeast artificial chromosome (YAC)based sequence-tagged site (STS)-content map spanning the CCM1 critical region was generated. A collection of YACs highly enriched for chromosome 7 (Green et al. 1995) was screened using 34 STS-specific polymerase chain reaction (PCR) assays. Information on the 34 STSs assigned to YAC clones is provided in Table 1 , with additional information such as PCR reaction conditions and complete DNA sequence available from GenBank and/or the Genome Data Base (GDB). Among the STSs were 11 corresponding to genetic markers, 13 derived from YACs (in particular, 12 from YAC insert ends), 6 developed from random chromosome 7 sequences, and 4 corresponding to expressed sequence tag (EST) or gene sequences. On the basis of analysis of the result- 
JOHNSON ET AL.

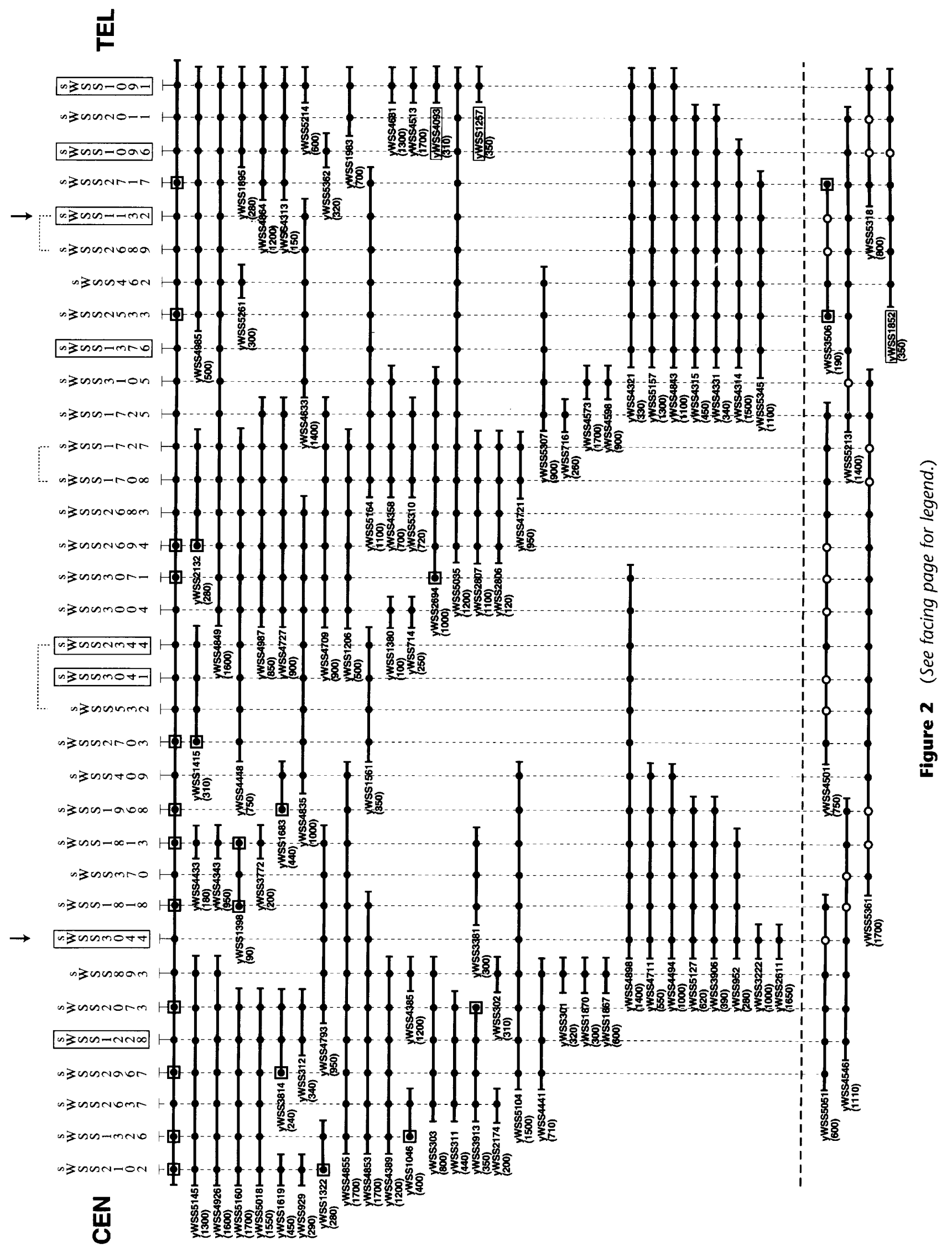




\section{FINE MAPPING OF IHE CAVERNOUS MALFORMAIION GENE CCMI}

ing STS content data using the program SEGMAP (Green and Green 1991; C.L. Magness and P. Green, unpubl.), the YAC contig shown in Figure 2 was deduced. This contig contained 92 YACs and provided a unique order for 30 of the 34 STSs. Original library positions of YACs derived from total human genomic libraries are listed in Table 2. Orientation of the contig relative to the centromere and telomere was determined through linkage mapping (see above) and radiation hybrid mapping (E.D. Green and D.R. Cox, unpubl.) of a subset of the STSs. Note that there was redundant YAC-based connectivity throughout the contig (i.e., there were two or more YACs connecting each adjacent pair of STSs), lending strong support for the relative order of STSs. The order of markers determined from the YAC contig was in complete agreement with the Centre d'Etude du Polymorphisme Humain (CEPH) family linkage map (Fig. 1). Three of the YACs in the contig (yWSS1257, yWSS1852, and yWSS4093) were found by fluorescence in situ hybridization (FISH) analysis to map within 7q21-q22 (Green et al. 1994), indicating that the CCM1 gene probably resides within this cytogenetic region.

\section{CCM Families (FCCM)}

A total of five families with a history of cavernous malformation were examined for this study, two Caucasian and three of Hispanic origin. In- formation documenting linkage to chromosome $7 \mathrm{q}$ in most of these families has been published previously (Dubovsky et al. 1995; Gil-Nagel et al. 1995a,b; Marchuk et al. 1995). One additional unpublished Hispanic family designated FCCM300 was also used. The pedigree for this family is presented in Figure 3. DNA was collected from eight affected and seven unaffected members of this family spanning three generations. All diagnoses in these individuals were confirmed with MR imaging.

DNA from the five families used in the study was analyzed initially using some 30 STRPs covering a $15-\mathrm{cM}$ region on chromosome $7 \mathrm{q}$ roughly spanning the interval from D7S440 (Mfd50) proximally to D7S1820 (GATA26D09) distally (see Dubovsky et al. 1995). Pairwise maximum lod scores for the families are displayed in Table 3 . Because of limited kindred size, not all of the pairwise lod scores were in excess of 3.0 , but all were at least consistent with linkage to $7 \mathrm{q}$.

\section{Shared Haplotypes}

Within each individual family, affected individuals shared broad haplotypes (Table 4). There is little overlap in haplotype between the two Caucasian families, FCCM1 and FCCM20, or between these families and the Hispanic families. However, the three Hispanic kindred, FCCM10, FCCM200, and FCCM300, shared alleles from

Figure 2 YAC contig containing the CCM1 critical region. The YAC-based STS content map of the CCM1 critical region of chromosome 7 is depicted, as deduced by SEGMAP/version 3.36 (Green and Green 1991; C.L. Magness and P. Green, unpubl.). The 34 STSs (see Table 1) mapped to the YAC clones are listed along the top. Of these STSS, 30 could be uniquely ordered based on the STS content of the YACS, with the groups of STSS not ordered relative to one another indicated by horizontal brackets above the STS names. Arrows indicate the positions of the two genetic markers [D7S2410 (sWSS3044) and D7S689 (sWSS1132)] that represent the flanking boundaries of the CCM1 critical region, as defined in this study. Also shown are the predicted positions of the centromere (CEN) and $7 q$ telomere (TEL) relative to the ends of the contig. Each of the 92 YAC clones is depicted by a horizontal bar, with its name given at left and estimated YAC size (in kb, measured by pulsed-field gel electrophoresis) provided in parenthesis. The presence of an STS in a YAC is indicated by a closed circle at the appropriate position. When an STS corresponds to the insert end of a YAC, a square is placed around the corresponding circle, both along the top (near the STS name) and at the end of the YAC from which it was derived. For the eight YACs at the bottom (below the horizontal broken line), one or more STS(s) expected to be present (based on the established STS order) was not detected as assessed by testing the individual YACs with the corresponding STS-specific PCR assays at least twice, and these are depicted as open circles at the appropriate positions. A subset of the YACs was isolated from a human-hamster hybrid cell-derived library (Green et al. 1995), with their original names as indicated. The remaining YACs were isolated from total human genomic libraries, and their original library locations are provided in Table 4. Boxes are placed around the names of the three YACs (yWSS1257, yWSS1852, and yWSS4093) that were found by FISH analysis to map to 7q21-q22. The contig is displayed in its uncomputed form, where YAC sizes are not used to estimate clone overlaps or STS spacing and all of the STSs are spaced in an equidistant fashion. In the computed form, where YAC sizes are used to estimate the relative distance separating each pair of adjacent STSs as well as the extent of clone overlaps, the total YAC contig appears to span just over $3.8 \mathrm{Mb}$. 


\section{Table 2. Original Well Locations of YACs Derived from Total Human Genomic Libraries}

\begin{tabular}{|l|l|l|}
\hline yWSS Name & Library & Location \\
\hline yWSS301 & WU & A133B8 \\
\hline yWSS302 & WU & A133C4 \\
\hline yWSS303 & WU & A171H5 \\
\hline yWSS311 & WU & D23F4 \\
\hline yWSS312 & WU & D78F7 \\
\hline yWSS2611 & CEPH & 763 A04 \\
\hline yWSS2694 & CEPH & $774 F 01$ \\
\hline yWSS2806 & CEPH & $784 A 08$ \\
\hline yWSS2807 & CEPH & $784 A 11$ \\
\hline yWSS3222 & CEPH & $850 G 03$ \\
\hline yWSS4312 & ICI & I66H1 \\
\hline yWSS4313 & ICI & I149D1 \\
\hline yWSS4314 & ICI & I323E10 \\
\hline yWSS4315 & ICI & I335A8 \\
\hline yWSS4331 & ICI & I66H1 \\
\hline yWSS4343 & CEPH & $740 G 04$ \\
\hline yWSS4358 & CEPH & $740 E 03$ \\
\hline yWSS4385 & CEPH & $750 F 01$ \\
\hline yWSS4389 & CEPH & $751 G 05$ \\
\hline yWSS4433 & CEPH & $764 G 11$ \\
\hline yWSS4441 & CEPH & $766 G 11$ \\
\hline yWSS4448 & CEPH & $769 D 05$ \\
\hline yWSS4494 & CEPH & $787 D 08$ \\
\hline yWSS4501 & CEPH & $791 A 02$ \\
\hline yWSS4513 & CEPH & $794 F 06$ \\
\hline yWSS4546 & CEPH & $807 E 11$ \\
\hline yWSS4573 & CEPH & $818 D 02$ \\
\hline yWSS4598 & CEPH & $843 B 02$ \\
\hline yWSS4633 & CEPH & $855 E 06$ \\
\hline yWSS4681 & CEPH & $871 D 08$ \\
\hline yWSS4709 & CEPH & $885 F 02$ \\
\hline yWSS4711 & CEPH & $885 G 06$ \\
\hline
\end{tabular}

\begin{tabular}{|l|l|l|}
\hline yWSS Name & Library & Location \\
\hline yWSS4721 & CEPH & 888 G09 \\
\hline yWSS4727 & CEPH & 890 C02 \\
\hline yWSS4793 & CEPH & $908 G 08$ \\
\hline yWSS4835 & CEPH & $918 E 08$ \\
\hline yWSS4843 & CEPH & 919 G04 \\
\hline yWSS4849 & CEPH & $921 \mathrm{G08}$ \\
\hline yWSS4853 & CEPH & $923 D 10$ \\
\hline yWSS4855 & CEPH & $923 H 12$ \\
\hline yWSS4864 & CEPH & $925 E 10$ \\
\hline yWSS4898 & CEPH & $931 G 04$ \\
\hline yWSS4926 & CEPH & 937 C10 \\
\hline yWSS4985 & CEPH & $947 A 11$ \\
\hline yWSS4987 & CEPH & $947 G 12$ \\
\hline yWSS5018 & CEPH & $952 D 01$ \\
\hline yWSS5035 & CEPH & $956 B 05$ \\
\hline yWSS5051 & CEPH & $960 E 10$ \\
\hline yWSS5104 & CEPH & $977 H 12$ \\
\hline yWSS5127 & CEPH & $743 B 02$ \\
\hline yWSS5145 & CEPH & $820 H 08$ \\
\hline yWSS5157 & CEPH & $881 H 05$ \\
\hline yWSS5160 & CEPH & $894 E 11$ \\
\hline yWSS5164 & CEPH & $904 G 08$ \\
\hline yWSS5213 & CEPH & $664 F 06$ \\
\hline yWSS5214 & CEPH & $965 E 12$ \\
\hline yWSS5261 & CEPH & $732 E 11$ \\
\hline yWSS5307 & CEPH & $722 D 09$ \\
\hline yWSS5310 & CEPH & $734 D 05$ \\
\hline yWSS5318 & CEPH & 669 C02 \\
\hline yWSS5345 & CEPH & $825 H 3$ \\
\hline yWSS5361 & CEPH & $966 F 4$ \\
\hline yWSS5362 & CEPH & $966 G 8$ \\
\hline
\end{tabular}

A subset of the YACs depicted in Fig. 2 were isolated from total human genomic libraries constructed at Washington University (Burke et al. 1987; Brownstein et al. 1989; Burke and Olson, 1991), CEPH (Albertsen et al. 1990; Dausset et al. 1992), or ICl (Anand et al. 1989, 1990). To facilitate cross-correlation of these latter YACs, each yWSS name is listed along with the original library and precise well location from which the corresponding clone was isolated. The remaining YACs depicted in Fig. 2 were isolated from a human-hamster hybrid cell-derived library (Green et al. 1995), with their original names and library locations as indicated in the contig.

showed a 12-base shift from the allele size seen in the other two Hispanic families.

\section{Recombination Events}

Key recombination events within three of the families are shown in Figure 4. In family FCCM1, individual 20 , an affected female, was recombinant with respect to her affected mother between markers D7S2410 and D7S2408. The crossover seen in this individual effectively defined the proximal boundary of the interval. From marker D7S2410 proximally, all the alleles were derived from the affected mother's unaffected chromosome. The phase of the maternal alleles was firmly established from analysis of the grandparental genotypes. The presence of two affected sibs who shared the mother's affected haplotype (individuals 19 and 21) was additional evidence for an informative recombination in individual 20 .

The distal boundary of the CCM1 interval was defined by a crossover in individual 16 from family FCCM200. Individual 16, an affected female, was recombinant with respect to her affected mother between markers D7S1813 and D7S689. Centromeric to D7S1813, the alleles were unambiguously from the maternal affected chromosome. Again, the affected grandmother helped to establish phase. Note that markers at the three loci immediately proximal to D7S689 (D7S558, D7S646, and D7S1789) were uninformative in this crossover.

Two crossovers in unaffected

several adjacent markers. All three Hispanic families shared a segment of conserved haplotype distal to marker D7S630.

The proximal end of this "Hispanic interval" is well defined by at least three independent allelic variations; at D7S2417, FCCM10 showed a 6-base shift compared with the other two Hispanic families, and at D7S2485, FCCM10 showed an 8-base shift. Finally, at D7S630, FCCM300 individuals provided additional support for the location of CCM1. A crossover in individual 11 from FCCM300 was located between loci D7S630 and D7S2408. Centromeric to D7S630, the alleles were clearly derived from the affected maternal chromosome, supporting the localization of CCM1 distal to D7S630. Another unaffected individual from FCCM300, individual 15, was recombinant at D7S652. Centromeric to D7S652, 


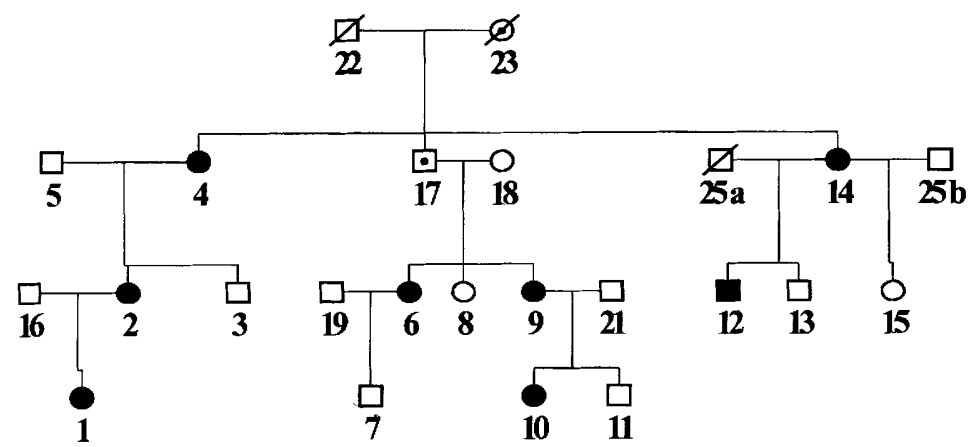

Figure 3 Pedigree for cavernous malformation family FCCM 300. FCCM 300 is of Hispanic origin and was collected at the Barrow Neurological Institute, Phoenix, AZ. DNA was collected from individuals 1 through 15 . (O, a) Affected inividuals confirmed by MR imaging studies. $(\bigcirc, \square)$ Unaffected individuals also confirmed by MR imaging studies. Symbols with a dot (individuals 17 and 23) represent obligate carriers.

the alleles were derived from the unaffected parental chromosome, putting CCM1 proximal to this locus. Even though penetrance of CCM is incomplete, the interval defined by crossovers in the unaffected individuals was still completely consistent with that defined in the affected individuals.

In addition to the recombinations shown in Figure 4, one crossover in FCCM200 and one in FCCM300 placed the CCM1 gene distal to D7S669 (afm286xf9) (data not shown; for linkage maps, see Gyapay et al. 1994; Dubovsky et al. 1995). Finally, another two crossovers in affected sibs from FCCM1 placed the gene distal to D7S524 (248ta5).

Whereas the contig shown in Figure 2 was deduced by SEGMAP without consideration of YAC sizes (thereby displaying STSs equidistant from one another), a similar analysis of the data by SEGMAP that accounted for YAC sizes suggests that the region covered by the contig spans just over $3.8 \mathrm{Mb}$. On the basis of this analysis, the interval between the key genetic markers D7S2410 (sWSS3044) and D7S689 (sWSS1132) is estimated to be just over $2 \mathrm{Mb}$. Taken together, the genetic and physical mapping results presented here delimit the CCM1 critical region to a 4-cM, 2-Mb interval of human chromosome $7 q 21-q 22$ that is contained within a highly redundant set of overlapping YAC clones.

\section{DISCUSSION}

The smallest interval shared by all affected individuals that can be defined by analysis of the crossovers in the families examined encompassed the polymorphic markers at loci D7S2410, D7S2408, D7S2409, D7S1813, D7S1789, D7S646, D7S558, and D7S689, a span of $\sim 4 \mathrm{cM}$ based on the linkage map or $\sim 2 \mathrm{Mb}$ based on the physical map. Additionally, the interval defined by crossovers in unaffected individuals is completely consistent with that defined in the affected individuals. Finally, the region of conserved haplotype shared by affected individuals in the three Hispanic families, which is independent of the observed crossovers, overlapped the interval of interest defined by these crossovers.

Within the most likely interval are four potential candidate genes, three expressed sequence tags of unknown function (EST00272, EST00631, and EST00979) and the cyclin-dependent kinase gene CDK6 (Bullrich et al. 1995). None of these genes are intuitively strong candidates for CCM1, but their location makes them of interest. Potential candidate genes defined in earlier papers, including genes encoding elastin, CD36, the mul-

\begin{tabular}{|c|c|c|c|c|c|}
\hline Family & $\begin{array}{l}\text { STRP/ } \\
\text { marker }\end{array}$ & $\begin{array}{l}\text { Max. } \\
\text { lod score }\end{array}$ & $\theta$ & Ethnicity & Reference \\
\hline FCCM-1 & D7S558 & 5.24 & 0.12 & Causacian & A. Gil-Nagel et al. (in prep.) \\
\hline FCCM-10 & D7S502 & 3.04 & 0.00 & Hispanic & Marchuk et al. (1995) \\
\hline FCCM-20 & D7\$479 & 0.99 & 0.03 & Caucasian & Marchuk et al. (1995) \\
\hline FCCM-200 & D7S804 & 4.19 & 0.00 & Hispanic & Dubovsky et al. (1995) \\
\hline FCCM -300 & D7S1813 & 2.53 & 0.00 & Hispanic & unpublished \\
\hline
\end{tabular}


Table 4. Shared Haplotypes Among CCM Families

\begin{tabular}{|c|c|c|c|c|c|c|c|}
\hline \multirow[b]{2}{*}{ cM } & \multirow{2}{*}{$\begin{array}{l}\text { STRP/ } \\
\text { marker }\end{array}$} & \multicolumn{2}{|c|}{ Caucasian } & \multicolumn{3}{|c|}{ Hispanic } & \multirow{2}{*}{$\begin{array}{l}\text { Shared } \\
\text { Hispanic } \\
\text { haplotype }\end{array}$} \\
\hline & & FCCM-1 & FCCM-20 & FCCM-10 & FCCM-200 & FCCM-300 & \\
\hline & D7S2417 & 170 & 170 & 170 & 164 & 164 & \\
\hline & D7S2481 & 205 & 205 & 205 & 205 & 205 & \\
\hline & D7S2485 & 92 & 92 & 92 & 100 & 100 & \\
\hline 0 & D7S630 & 220 & 202 & 218 & 218 & 206 & \\
\hline 1.5 & D7S492 & 147 & 147 & 151 & 151 & 151 & 151 \\
\hline \multirow[t]{3}{*}{2.2} & D7S2410 & 265 & 269 & 279 & 279 & 279 & 279 \\
\hline & D7S2408 & 198 & 198 & 198 & 198 & 198 & 198 \\
\hline & D7S2409 & 102 & 102 & 98 & 98 & 98 & 98 \\
\hline \multirow[t]{4}{*}{5} & D7S1813 & 131 & 137 & 137 & 137 & 137 & 137 \\
\hline & D7S1789 & 131 & 131 & 137 & 137 & 137 & 137 \\
\hline & D7S646 & 183 & 189 & 185 & 185 & 185 & 185 \\
\hline & D7S558 & 103 & 111 & 107 & 107 & 107 & 107 \\
\hline \multirow[t]{3}{*}{6.2} & D7S689 & 133 & 129 & 129 & 129 & 129 & 129 \\
\hline & D7S657 & 250 & 260 & 246 & 246 & 246 & 246 \\
\hline & D7S652 & 273 & 275 & 277 & 277 & 277 & 277 \\
\hline 7.3 & D7S1820 & 252 & 252 & 252 & 252 & 252 & 252 \\
\hline 7.8 & COL1A2 & 277 & 277 & 273 & 273 & 273 & 273 \\
\hline
\end{tabular}

The numbers in the first column represent the cumulative positions in $\mathrm{cM}$ for markers on the linkage map (see Fig. 1). Other values indicate the sizes in nucleotides of the alleles linked to the cavernous malformation mutation (i.e., "affected alleles") in the affected members of the indicated families. Allele size was determined by comparison to amplified DNA from CEPH family members 1331-01 and 1331-02. Marker order was determined by both linkage and physical mapping (Figs. 1 and 2).

tiple drug resistance proteins 1 and 3 , and collagen $1 \mathrm{~A} 2$, have all been eliminated from consideration by the results presented here, because each of these genes has been definitively mapped to a YAC contig other than the one shown in Figure 2 (E.D. Green, unpubl.). A search of the portions of mouse chromosomes 5 and 6 syntenic to human $7 q$ revealed no seizure or vascular deformation genes nor any obvious candidate genes for cavernous malformations within the relevant intervals (Grzeschik et al. 1994).

Günel and co-workers (1995) recently described two families with a history of cavernous malformations. In their Hispanic family, two independent crossovers clearly indicated that
CCM1 lies distal to the elastin locus. These data were consistent with our localization of CCM1 to a more distal segment of 7q. In their other family, a Caucasian kindred of European decent, crossovers in two affected individuals placed CCM1 proximal to D7S644 (afm234xc7) and D7S802 (Mfd340). Both of these loci are considerably proximal (4-9 cM) to the most likely location for CCM1 described here. A possible explanation for this discrepancy (suggested by Günel et al. 1995) is that the genetic defect in their European CCM family is unlinked to $7 \mathrm{q}$. The maximum pairwise lod score obtained for a $7 \mathrm{q}$ marker with this family was only 1.1 ; if confirmed, this would be the first example of locus heterogeneity for CCM.

Figure 4 Pedigree of selected members from FCCM1, FCCM200, and FCCM300 showing haplotypes for individuals with informative crossovers and their immediate family members. Arrows indicate the individuals with informative crossovers. The solid bar indicates those alleles that are linked to the cavernous malformation mutation (i.e., "affected alleles"). In the case of individuals with crossovers, the solid bar is used to depict only those alleles that can be unambiguously linked to the parental "affected" haplotype. The order of the chromosome 7q STRPs used to define this region (also displayed in a box in the lower right corner of this figure) was from top to bottom: D7S2417, D7S2481, D7S2485, D7S630, D7S492, D7S2410, D7S2408, D7S2409, D7S1813, D7S1789, D7S646, D7S558, D7S689, D7S657, D7S652, D7S1820, and COL1A2. 
FINE MAPPING OF THE CAVERNOUS MALFORMATION GENE CCMI

Cavernous malformations affect tens of millions of people worldwide. With the advent of MR imaging, they are being increasingly recognized as a cause of seizures and other neurologic impairments. Only $15 \%-20 \%$ of patients with MR-documented lesions remain asymptomatic throughout their lives. The presence of multiple lesions increases the risk of complications in the
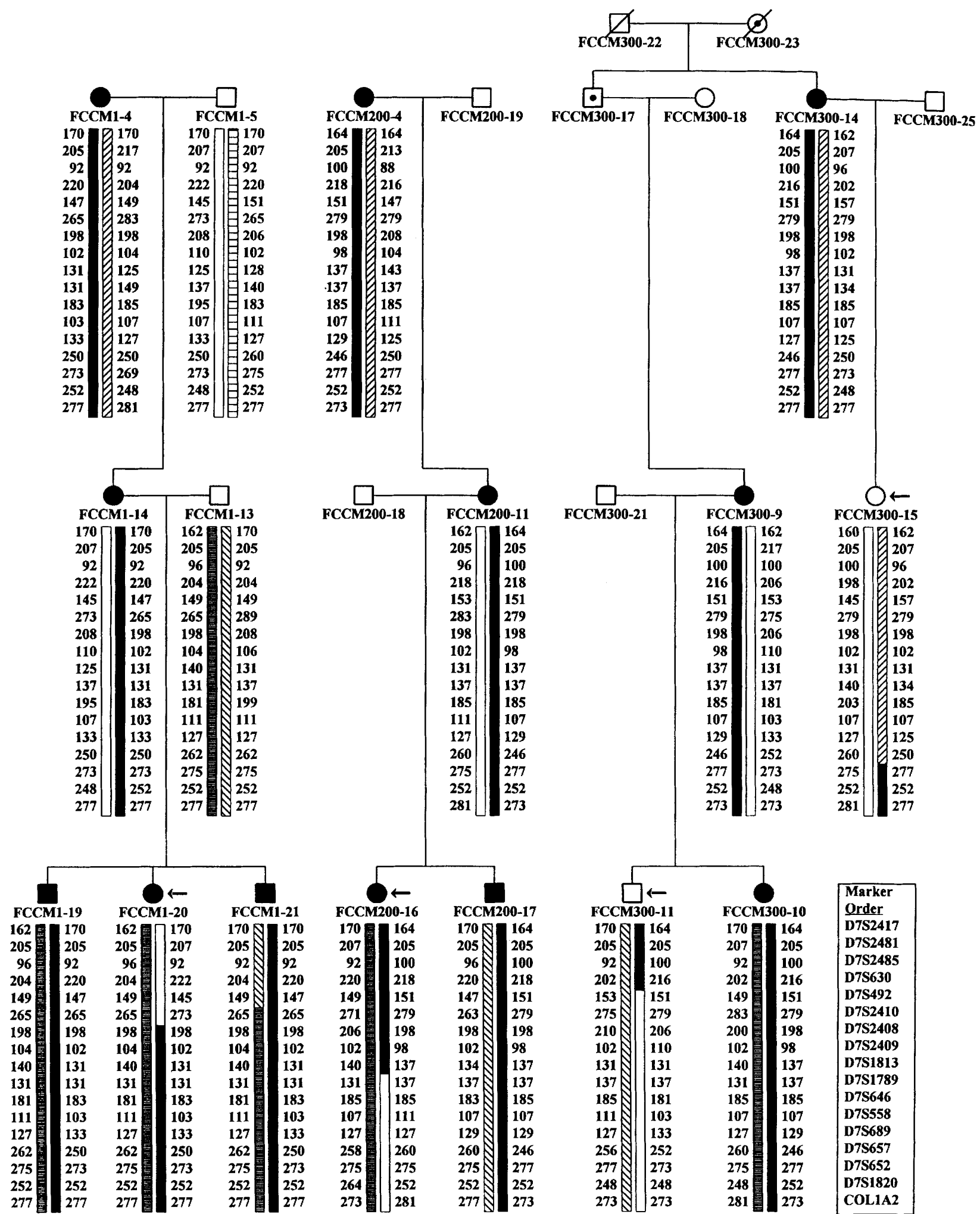

Figure 4 (See facing page for legend.) 
familial form of this disease. In cases of familial epilepsy where there is an autosomal dominant pattern of inheritance, it will be important to exclude CCM as an etiologic cause. Identification of the CCM1 gene may ultimately lead to significantly improved therapy for this disorder. Efforts are currently under way to collect additional CCM families, to further narrow the CCM1 critical interval, and to determine all possible candidate genes in that region.

\section{METHODS}

\section{YAC-based STS Content Mapping}

STS-specific PCR assays were developed and optimized essentially as described (Green and Green 1991; Green et al.

1991, 1994; Green 1993). Each STS is named using the prefix sWSS followed by a unique number. For the genetic marker-specific STSs, the oligonucleotide primers used for testing YAC clones corresponded either to those employed for genotype analysis or those designed [most often with the computer program OSP (Hillier and Green 1991)] using the DNA sequence available in GenBank or provided by Weissenbach et al. (1992).

Most of the YACs used in this study were derived from a collection of clones highly enriched for human chromosome 7 [the chromosome 7 YAC resource (Green et al. 1995)] using a PCR-based screening strategy (Green and Olson 1990; Green et al. 1995). Among these YACs are clones derived from a chromosome 7-containing humanhamster hybrid cell line and clones isolated from total genomic libraries. Each YAC is named using the prefix yWSS followed by a unique number.

\section{Phenotypic Evaluation of Family Members}

Individual family members were considered affected if they demonstrated the positive presence of CCM on MR images whether they were symptomatic or not. Where possible, the results of the MR imaging were confirmed either at the time of surgery or at autopsy. Procedures for capturing and analyzing MR images have been described previously (Rigamonti et al. 1987; Zabramski et al. 1994). Some individuals were studied using cerebral angiography in addition to MR imaging.

\section{Sample Collection and Genotyping}

A detailed informed consent form approved by each participating institution's Institutional Review Board (IRB) was presented to all individuals participating in these studies. After obtaining informed consent, two $10-\mathrm{ml}$ blood samples were drawn by venipuncture from the family members. Genomic DNA was extracted from the lymphocytes as described previously (Kurth et al. 1993). Genotyping with STRPs was completed using methods reported previously (Weber et al. 1993). Markers were developed either at Genethon (Weissenbach et al. 1992; Gyapay et al. 1994; J. Weissenbach, pers. comm.), at Marshfield (Weber et al. 1990; Murray et al. 1994), or within the Cooperative Human Linkage Center (CHLC) (Murray et al. 1994). The marker at COL1A2 (collagen 1A2) locus was developed by Chi and colleagues (1992).

\section{Linkage Mapping, Statistical Analysis, and Haplotype Analysis}

Linkage maps were constructed using CEPH reference family genotyping data generated at Marshfield and data obtained from versions 6 and 7 of the CEPH data bases, as well as unpublished results (J. Weissenbach, pers. comm.). Maps were built using the program CRIMAP (Lander and Green 1987). Pairwise lod scores were computed using LINKAGE version 5.03b (Lathrop and Lalouel 1984). Analysis of haplotype was done both manually and using the Cyrillic software package (Cherwell Scientific).

\section{ACKNOWLEDGMENTS}

We thank the various members of each of our study families for their cooperation and enthusiastic participation. We thank Dr. Gerry Bouffard for computational assistance on the physical mapping studies and members of E.D.G.'s laboratory for their assistance in constructing the YACbased STS content map. Joann Snyder and Beth EggersSodlet at the Barrow Neurological Institute (Phoenix, AZ) were essential for collecting samples and isolating DNA from both FCCM200 and the new family presented here, FCCM300. This work was supported by National Institutes of Health grant NS16308, the Barrow Neurological Institute, the Arizona Disease Control Research Commission (contract 9516), and the American Heart Association.

The publication costs of this article were defrayed in part by payment of page charges. This article must therefore be hereby marked "advertisement" in accordance with 18 USC section 1734 solely to indicate this fact.

\section{REFERENCES}

Albertsen, H.M., H.H. Abderrahim, H.M. Cann, J. Dausset, D. Le Paslier, and D. Cohen. 1990. Construction and characterization of a yeast artificial chromosome library containing seven haploid genome equivalents. Proc. Natl. Acad. Sci 87: 4256-4260.

Allard, J.C., F.H. Hochberg, P.D. Franklin, and A.P. Carter. 1989. Magnetic resonance imaging in a family with hereditary cerebral arteriovenous malformations. Arch. Neurol. 46: 184-187.

Anand, R., A. Villasante, and C. Tyler-Smith. 1989. Construction of yeast artificial chromosome libraries with large inserts using fractionation by pulsed-field gel electrophoresis. Nucleic Acids Res. 17: 3425-3433.

Anand, R., J.H. Riley, R. Butler, J.C. Smith, and A.F. Markham. 1990. A 3.5 genome equivalent multi access YAC library: Construction, characterization, screening and storage. Nucleic Acids Res. 18: 1951-1956. 


\section{FINE MAPPING OF IHE CAVERNOUS MALFORMATION GENE CCMI}

Boon, L.M., J.B Muilliken, M. Vikkula, H. Watkins, J. Seidman, B.R. Olsen, and M.L. Warman. 1994. A familial venous malformation locus is on chromosome 9 p. Am. J. Hum. Genet. 55: A181.

Brownstein, B.H., G.A. Silverman, R.D. Little, D.T. Burke, S.J. Korsmeyer, D. Schlessinger, and M.V. Olson. 1989. Isolation of single-copy human genes from a library of yeast artificial chromosome clones. Science

244: $1348-1351$.

Bullrich, F., T.K. MacLachlair, N. Sang, T. Druck, M.L. Veronese, S.L. Allen, N. Chiorazzi, A. Koff, K. Heubner, C.M. Croce, and A. Giordano. 1995. Chromosomal mapping of members of the cdc2 family of protein kinases, cdk3, cdk6, PISSLRE, and PITALRE, and a cdk inhibitor, $p 27^{\mathrm{Kip}}$, to regions involved in human cancer. Cancer Res. 55: 1199-1205.

Burke, D.T. and M.V. Olson. 1991. Preparation of clone libraries in yeast artificial-chromosome vectors. In Methods in enzymology, guide to yeast genetics and molecular biology (ed. C. Guthrie and G.R. Fink), Vol. 194, pp. 251-270. Academic Press, San Diego, CA.

Burke, D.T., G.F. Carle, and M.V. Olson. 1987. Cloning of large segments of exogenous DNA into yeast by means of artificial chromosome vectors. Science 236: $806-812$.

Chi, D.D., A.V. Hing, C. Helms, T. Steinbrueck, S.K. Mishra, and H. Donis-Keller. 1992. Two chromosome 7 dinucleotide repeat polymorphisms at gene loci epidermal growth factor receptor (EGFR) and proa2 (1) collagen (COL1A2). Hum. Mol. Genet. 1: 135.

Curling, O.D. Jr., D.L. Kelly Jr., A.D. Elster, and T.E. Craven. 1991. An analysis of the natural history of cavernous angiomas. J. Neurosurg. 75: 702-708.

Dausset, J., P. Ougen, H. Abderrahim, A. Billault, J.-L. Sambucy, D. Cohen, and D. Le Paslier. 1992. The CEPH YAC library. Behring Inst. Mitt. 91: 13-20.

Dobyns, W.B., V.V. Michels, R.V. Groover, B. Mokri, J.C. Trautmann, G.S. Forbes, and E.R. Laws Jr. 1987. Familial cavernous malformations of the central nervous system and retina. Ann. Neurol. 21: 578-583.

Dubovsky, J., J.M. Zabramski, J. Kurth, R.F. Spetzler, S.S. Rich, H.T. Orr, and J.L. Weber. 1995. A gene responsible for cavernous malformations of the brain maps to chromosome 7q. Hum. Mol. Genet. 4: 453-458.

Gil-Nagel, A., K.J. Wilcox, J.M. Stewart, V.E. Anderson, I.E. Leppik, and S.S. Rich. 1995a. Familial cerebral cavernous angioma: Clinical analysis of a family and phenotyic classification. Epilepsy Res. 21: 27-36.

Gil-Nagel, A., J. Dubovsky, K.J. Wilcox, J.M. Stewart, V.E. Anderson, I.E. Leppik, H.T. Orr, E.W. Johnson, J.L. Weber, and S.S. Rich. 1995b. Familial cerebral angioma: An autosomal dominant gene localized to a $15 \mathrm{cM}$ interval on human chromosome 7q. Ann. Neurol. (in press).

Green, E.D. 1993. Physical mapping of human chromosomes: Generation of chromosome-specific sequence-tagged sites. In Methods in molecular genetics: Gene and chromosome analysis (part A) (ed. K.W. Adolph), Vol. 1, pp. 192-210. Academic Press, San Diego, CA.

Green, E.D. and P. Green. 1991. Sequence-tagged site (STS) content mapping of human chromosomes: Theoretical considerations and early experiences. $P C R$ Methods Applic. 1: 77-90.

Green, E.D. and M.V. Olson. 1990. Systematic screening of yeast artificial-chromosome libraries by use of the polymerase chain reaction. Proc. Natl. Acad. Sci. 87: 1213-1217.

Green, E.D., R.M. Mohr, J.R. Idol, M. Jones, J.M. Buckingham, L.L. Deaven, R.K. Moyzis, and M.V. Olson. 1991. Systematic generation of sequence-tagged sites for physical mapping of human chromosomes: Application to the mapping of human chromosome 7 using yeast artificial chromosomes. Genomics 11: 548-564.

Green, E.D., J.R. Idol, R.M. Mohr-Tidwell, V.V. Braden, D.C. Peluso, R.S. Fulton, H.F. Massa, C.L. Magness, A.M. Wilson, J. Kimura, J. Weissenbach, and B.J. Trask. 1994. Integration of physical, genetic and cytogenetic maps of human chromosome 7: Isolation and analysis of yeast artificial chromosome clones for 117 mapped genetic markers. Hum. Mol. Genet. 3: 489-501.

Green, E.D., V.V. Braden, R.S. Fulton, R. Lim, M.S. Ueltzen, D.C. Peluso, R.M. Mohr-Tidwell, J.R. Idol, L.M. Smith, I. Chumakov, D. Le Paslier, D. Cohen, T. Featherstone, and P. Green. 1995. A human chromosome 7 yeast artificial chromosome (YAC) resource: Construction, characterization, and screening. Genomics 25: 170-183.

Grzeschik, L.-H., L.-C. Tsui, and E.D. Green. 1994. Report of the first international workshop on human chromosome 7 mapping 1993. Cytogenet. Cell Genet. 65: $52-62$.

Günel, M., I.A. Awad, J. Anson, and R.P. Lifton. 1995. Mapping of a gene causing cerebral cavernous malformation to 7q11.2-q21. Proc. Natl. Acad. Sci. 92: $6620-6624$.

Gyapay, G., J. Morissette, A. Vignal, C. Dib, C. Fizames, P. Millasseau, S. Marc, G. Bernardi, M. Lathrop, and J. Weissenbach. 1994. The 1993-94 Généthon human genetic linkage map. Nature Genet. 7: 246-339.

Hayman, L.A., R.A. Evans, R.E. Ferrell, L.M. Fahr, P. Ostrow, and V.M. Riccardi. 1982. Familial cavernous angiomas: Natural history and genetic study over a 5-year period. Am. J. Med. Genet. 11: 147-160.

Hillier, L. and P. Green. 1991. OSP: A computer program 


\section{JOHNSON ET AL.}

for choosing PCR and DNA sequencing primers. PCR Methods Applic. 1: 124-128.

Kurth, J.H., M.C. Kurth, S.E. Poduslo, and J.D. Schwankhaus. 1993. Association of monoamine oxidase B allele with Parkinson's disease. Annu. Neurol. 33: $368-372$.

Lander, E.S. and P. Green. 1987. Construction of multilocus genetic linkage maps in humans. Proc. Natl. Acad. Sci. 84: 2363-2367.

Lathrop, G.M. and J.M. Lalouel. 1984. Easy calculations of Lod scores and genetic risks on small computers. Am. J. Hum. Genet. 36: 460-465.

Malik, S., B.H. Cohen, J. Robinson, A. Fried, and C.A. Sila. 1992. Progressive vision loss: A rare manifestation of familial cavernous angiomas. Arch. Neurol. 49: $170-173$.

Marchuk, D.A., C.J. Gallione, L.A. Morrison, C.L. Clericuzio, B.L. Hart, B.E. Kosofsky, D.N. Louis, J.F. Gusella, L.E. Davis, and V.L. Prenger. 1995. A locus for cerebral cavernous malformations maps to chromosome $7 \mathrm{q}$ in two families. Genomics 28: $311-314$.

McCormick, W.F. 1984. Pathology of vascular malformations. In Intracranial arteriovenous malformations (ed. C.B. Wilson and B.M. Stein). Williams and Wilkins, Baltimore, MD.

Murray, J. C., K.H. Buetow, J.L. Weber, S. Ludwigsen, T. Scherpbier-Heddema, F. Manion, J. Quillen, V.C. Sheffield, S. Sunden, G.M. Duyk, J. Weissenbach, G. Gyapay, C. Dib, J. Morrissette, G.M. Lathrop, A. Vignal, R. White, N. Matsunami, S. Gerken, R. Melis, H. Albertsen, R. Plaetke, S. Odelberg, D. Ward, J. Dausset, D. Cohen, and H. Cann. 1994. A comprehensive human linkage map with centimorgan density. Science 265: 2049-2054.

Otten, P., G.P. Pizzolato, B. Rilliet, and J. Berney. 1989. 131 cases of cavernous angioma (cavernomas) of the CNS, discovered by retrospective analysis of 24,535 autopsies. Neurochirurgie 35: 82-83.

Rigamonti, D., B.P. Drayer, P.C. Johnson, M.N. Hadley, J.M. Zabramski, and R.F. Spetzler. 1987. The MRI appearance of cavernous malformations (angiomas). $J$. Neurosurg. 67: 518-524.

Rigamonti, D., M.N. Hadley, B.P. Drayer, P.C. Johnson, K. Hoenig-Rigamonti, J.T. Knight, and R.F. Spetzler. 1988. Cerebral cavernous malformations: Incidence and familial occurrence. N. Engl. I. Med. 319: 343-347.

Robinson, J.R., I.A. Awad, and J.R. Little. 1991. Natural history of the cavernous angioma. J. Neurosurg. 75: 709-714.

Simard, J.M., F. Garcia-Bengochea, W.E. Ballinger Jr., J.P. Mickle, and R.G. Quisling. 1986. Cavernous angioma: A review of 126 collected and 12 new clinical cases. Neurosurgery 18: 162-172.

Villani, R.M., C. Arienta, and M. Caroli. 1989. Cavernous angiomas of the central nervous system. J. Neurosurg. Sci. 33: $229-252$.

Voight, K. and M.G. Yasargil. 1976. Cerebral cavernous haemangiomas or cavernomas. Neurochirurgia 19: 59-68.

Weber, J.L., A.E. Kwitek, and P.D. May. 1990. Dinucleotide repeat polymorphisms at the D7S435 and D7S440 loci. Nucleic Acids Res. 18: 4039.

Weber, J.L., Z. Wang, K. Hansen, M. Stephenson, C. Kappel, S. Salzman, P.J. Wilkie, B. Keats, N.C. Dracopoli, B.F. Brandriff, and A.S. Olsen. 1993. Evidence for human meiotic recombination interference obtained through construction of a short tandem repeat-polymorphism linkage map of chromosome 19. Am. J. Hum. Genet. 53: 1079-1095.

Weissenbach, J., G. Gyapay, C. Dib, A. Vignal, J. Morissette, P. Millasseau, G. Vaysseix, and M. Lathrop. 1992. A second-generation linkage map of the human genome. Nature 359: 794-801.

Zabramski, J.M., T.M. Wascher, R.F. Spetzler, B. Johnson, J. Goldfinos, B.P. Drayer, B. Brown, D. Rigamonti, and G. Brown. 1994. The natural history of familial cavernous malformations: Results of an ongoing study. $J$. Neurosurg. 80: 422-432.

Received August 25, 1995; accepted October 6, 1995. 


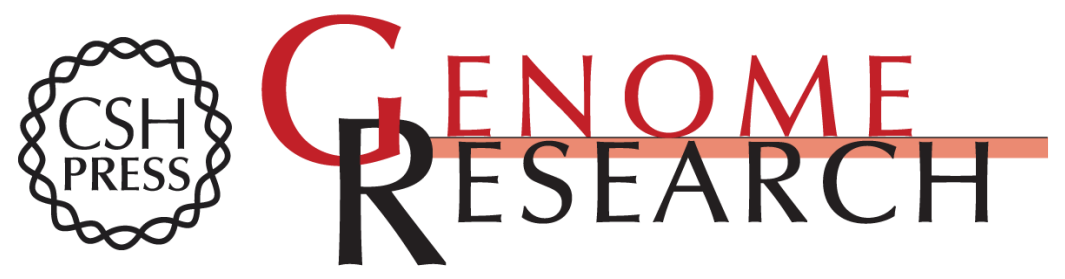

\section{Refined localization of the cerebral cavernous malformation gene (CCM1) to a 4-cM interval of chromosome 7q contained in a well-defined YAC contig.}

E W Johnson, L M lyer, S S Rich, et al.

Genome Res. 1995 5: 368-380

Access the most recent version at doi:10.1101/gr.5.4.368

References This article cites 41 articles, 7 of which can be accessed free at:

http://genome.cshlp.org/content/5/4/368.full.html\#ref-list-1

License

Email Alerting Receive free email alerts when new articles cite this article - sign up in the box at the Service top right corner of the article or click here.

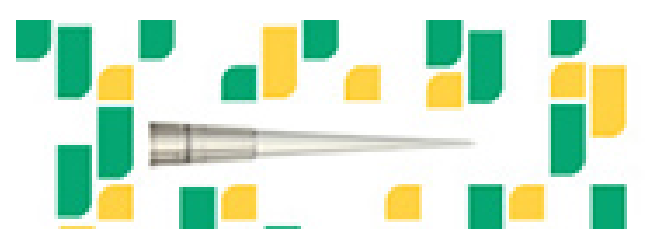

Focused on your science.

To subscribe to Genome Research go to:

https://genome.cshlp.org/subscriptions 